\title{
High pregnancy incidence and low contraceptive use among a prospective cohort of female entertainment and sex workers in Phnom Penh, Cambodia
}

Putu Duff',2,5, Jennifer L. Evans ${ }^{3}$, Ellen S. Stein ${ }^{3}$, Kimberly Page ${ }^{3,4}$, Lisa Maher ${ }^{5^{*}}$ on behalf of the Young Women's Health Study Collaborative

\begin{abstract}
Background: While HIV and unintended pregnancies are both occupational risks faced by female sex workers, the epidemiology of pregnancy and its drivers in this population remains understudied. This includes Cambodia, where the drivers of pregnancy among female entertainment and sex workers (FESW) remain unknown. The current study aimed to examine factors associated with incident pregnancy, as well as describe contraceptive use among FESW in Phnom Penh, Cambodia.

Methods: This analysis drew from the Young Women's Health Study (YWHS)-2, a 12-month observational cohort of 220 FESW aged 15-29 years, conducted between August 2009 and August 2010. Interviewer-administered questionnaires were conducted at baseline and quarterly thereafter, alongside HIV and pregnancy testing. Bivariate and multivariable extended Cox regression analysis was used to examine correlates of incident pregnancy.

Results: At baseline, $6.8 \%$ of participants were pregnant, and only $10.8 \%$ reported using hormonal contraceptives, with $11.3 \%$ reporting an abortion in the past 3 months. Pregnancy incidence was high, at 22/100 person-years (95\% Cl: 16.3-30.1). In multivariable analysis, younger age (19-24 years versus 25-29 years) (Adjusted Hazards Ratio (AHR): 2.28; 95\% Confidence Interval (CI) 1.22-4.27), lower income (400,000-600,000 Riel ( $\leq 150 \$$ USD) versus $>600,000$ Riel (> 150\$USD)) (AHR 2.63; 95\% CI 1.02-6.77) positively predicted pregnancy, while higher self-reported condom self-efficacy were associated with reduced pregnancy incidence (AHR 0.89; 95\% Cl 0.81-0.98).

Conclusions: Results document high incidence of pregnancy and unmet reproductive health needs among FESWs in Cambodia. Findings point to an urgent need for multi-level interventions, including venue-based HIV/STI and violence prevention interventions, in the context of legal and policy reform. High pregnancy incidence in this population may also undermine recruitment and retention into HIV prevention intervention trials. The exploration of innovative and comprehensive sex worker-tailored sexual and reproductive health service models, also as part of HIV prevention intervention trials, is warranted.
\end{abstract}

Keywords: Pregnancy, Reproductive health, Sex work, Cambodia, Cohort study, prevention trials

\footnotetext{
* Correspondence: Imaher@kirby.unsw.edu.au; http://www.kirby.unsw.edu.au

${ }^{5}$ Kirby Institute for Infection and Immunity (formerly the National Centre in

HIV Epidemiology and Clinical Research), UNSW Australia I, Wallace Wurth

Building, Sydney, NSW 2052, Australia

Full list of author information is available at the end of the article
}

(c) The Author(s). 2018 Open Access This article is distributed under the terms of the Creative Commons Attribution 4.0 International License (http://creativecommons.org/licenses/by/4.0/), which permits unrestricted use, distribution, and reproduction in any medium, provided you give appropriate credit to the original author(s) and the source, provide a link to the Creative Commons license, and indicate if changes were made. The Creative Commons Public Domain Dedication waiver (http://creativecommons.org/publicdomain/zero/1.0/) applies to the data made available in this article, unless otherwise stated. 


\section{Background}

Pregnancy in women at high risk of HIV is an important issue, with unprotected sex as the primary exposure for both HIV and pregnancy. While previous epidemiological research among women engaged in transactional sex has largely focused on risk of HIV and other sexually transmitted infections (STIs), a growing number of studies have begun to examine the broader reproductive health need of women engaged in transactional sex, including pregnancy [1-4]. Recent studies among women in engaged in transactional sex have documented lifetime pregnancy prevalence ranging between $70 \%$ and $90 \%$ [1, 3, 5-7], many of which are unintended pregnancies $[7,8]$. The prevalence of unintended pregnancies among women engaged in transactional sex is high - up to $86 \%$ in some studies [3] yet recent research indicates that many women engaged in transactional sex have a strong desire to have children [9], with pregnancy intentions similar to those of women in other occupations [10].

The high prevalence of pregnancy among women engaged in transactional sex also has important implications for the success of HIV prevention trials, which often enroll high-risk sexually active women, some of which target women engaged in transactional sex. Understanding the incidence and correlates of pregnancy among women involved in transactional sex is therefore critical, as pregnancy intention is often an exclusion criterion and actual pregnancy typically results in study product discontinuation (if the study product is considered potentially harmful to a pregnant woman or her fetus), potentially impacting the success of the trial, as well as the efficacy of subsequent interventions. Increased understanding of the drivers of pregnancy among women engaged in transactional sex is critical in developing sexual and reproductive health (SRH) services tailored to the specific needs of women engaged in transactional sex [11]. However, there remains a research gap on the prevalence and correlates of pregnancy among women working in entertainment venues with high-risk sexual patterns as well as women engaged in commercial sex. The few studies that have examined correlates of pregnancy, have found that individual and interpersonal factors such as previous history of abortion, having a steady intimate partner [12], experiencing violence [13] and alcohol/illicit drug use [12, 14] were associated with unintended pregnancy in this population.

In Cambodia, women engaged in high-risk and transactional sex are a heterogeneous group working in variety of environments and venues, whom collectively can be referred to as female entertainment and sex workers (FESW) $[15,16]$. Empirical data on pregnancy among FESW remain limited. Previous work by Delvaux [8] and colleagues highlighted low knowledge around SRH and limited access to reproductive health services among brothel-based women engaged in transactional sex in Phnom Penh, underscoring a need to examine the drivers of pregnancy in this population. Moreover, little is known about the pregnancy outcomes of FESW following the implementation of the 2008 'Law on Suppression of Human Trafficking and Sexual Exploitation' [17]. The 'Trafficking Law' effectively criminalized the selling and purchase of sex, by prohibiting almost all aspects of sex work including: public solicitation, procurement of prostitution, management of a sex work venue and the provision of premises for prostitution [18]. The passage of this law resulted in increased police crackdowns and brothel closures, and led to the displacement of FESW to entertainment venues, streets and guesthouses, where they lacked protections from peers and management [16]. In these new settings, FESW have reported increased vulnerability to client-perpetrated violence and a reduced ability to negotiate client condom use [16]. The displacement of FESW to diverse settings and the associated disruption of peer networks has been found to reduce the reach of HIV prevention and service delivery $[16,19]$, access to health services and condoms [16], and may also have had an impact on unintended pregnancy rates.

Given the dearth of research examining the correlates of pregnancy, particularly within the Cambodian context, this longitudinal study aimed to determine the factors associated with time to pregnancy among FESWs working in Phnom Penh, Cambodia over a twelve-month period. While our overall goal was to determine the set of factors that best describe incident pregnancy, we hypothesized that the following could potentially be associated with reduced time to pregnancy: marital status, young age and low parity, alcohol/illicit drug use, intimate partner violence and condom non-use by non-paying partners and clients.

\section{Methods \\ Study design and setting}

The data from this study were drawn from the Young Women's Health Study 2 (YWHS-2), a prospective cohort of young women engaged in sex work across a variety of venues and settings in Phnom Penh, Cambodia. [15] The YWHS was led by a multidisciplinary team including Cambodian Women's Development Association (CWDA), the National Center for HIV/AIDS, Dermatology and STD (NCHADS), the University of California, San Francisco (UCSF) in the United States, and the Kirby Institute at the University of New South Wales (UNSW) in Australia.

The study design and recruitment procedures are described in detail elsewhere [15]. Briefly, eligibility criteria included: being biologically female (aged 15-29), Khmer language comprehension, working in a sex work or entertainment venue and having two or more sexual partners in the last month or engaging in transactional sex 
(defined as having exchanged sex for money, drugs, or other goods or services) in the past three months, with plans of remaining in Phnom Penh throughout the course of the one-year study. Trained staff members recruited a convenience sample of women engaged in sex work from a variety of locations including: 1) YWHS information meetings held by CWDA; 2) neighbourhood-based outreach; and 3) referrals by previous participants or community groups. All study participants provided voluntary informed consent prior to enrolment in the study.

\section{Data collection}

Between 2009 and 2010, study participants visited the YWHS clinic at baseline and quarterly thereafter, where they completed a structured questionnaire, administered in Khmer by trained interviewers. The questionnaire elicited a wide range of information including sociodemographic characteristics (e.g., age, education, marital status), individual and interpersonal factors such as alcohol and drug use, interpersonal violence as well as sex work factors including occupational and sexual risk history, reproductive health and STI/HIV prevention (e.g., STI infection, contraceptive use and pregnancy). Staffed by a team of health care professionals, including a physician, nurses, counselors and a laboratory technician, all study participants attending the YWHS clinic for interviews were also tested for HPV and provided with STI treatment free of charge. Participants who tested positive for HPV or HIV were referred to local health providers for no-cost medical assessment and treatment.

All participants underwent voluntary client-centred riskreduction counseling prior to testing. HIV serology testing, using two rapid tests: Uni-Gold Recombigen HIV rapid HIV test (Trinity Biotech USA, Jamestown, New York, USA) and the Clairview HIV $1 \frac{1}{2}$ STAT-PAK (Inverness Medical Diagnostics, Waltham, Massachusetts, USA). HIV1 immunoblot was used to confirm HIV serodiscordant samples. All participants who tested negative for HIV and were not pregnant were offered HPV vaccination. Study participants were provided free transport to interview sites and remunerated (US\$5) for their time and expertise, regardless of whether they had or had not received the HPV vaccine. Ethical approval was obtained from the Institutional Review Board of the Committee on Human Research at the University of California, San Francisco, the Cambodian National Ethics Committee and the University of New South Wales Human Research Ethics Committee, aligned with both national and institutional ethical standards and the Helsinki Declaration of 1975 (revised in 2000). The Cambodian and U.S. IRB deemed the inclusion of minors ethical and waived requirement for parental consent based on the minimal risk posed by study procedures and potential for direct benefit to participants. Informed consent procedures following international guidelines (Declaration of Helsinki, and Council for International Organizations of Medical Sciences (CIOMS) with WHO)) were conducted in Khmer, by trained research personnel and with ongoing consultative supervision and training from staff of Cambodia National Center for HIV AIDS, and STDs (NCHADS) STD Clinic in Phnom Penh, Cambodia.

\section{Measures \\ Dependent variable}

The primary dependent variable, incident pregnancy, was based on a 'Yes' response to the question, 'As far as you know, are you pregnant now?' which was asked at each three-monthly follow-up.

\section{Independent variables}

Independent variables were considered based on a priori knowledge of their associations with pregnancy, including among women engaged in transactional sex, in the literature. Age and education (number of years in school) were considered fixed variables, and all other variables were considered time-variant and updated at every quarterly followup. Other socio-demographic variables included marital status (defined as living together (married), living together (not married) and living alone (divorced, widowed and single)) and number of children (measured continuously). Individual sexual and substance use patterns were also considered, such as number of days participants drank alcohol in the last month (measured continuously), self reported amphetamine-type stimulant (ATS) use in the last 3 months, including crystal (ice) and yama. We also included a 6-item scale for measuring self-efficacy for negotiating condom use, modified for the sex work context [20]. The scale included questions such as: "I can ask a new private partner to use condoms" and "I can refuse sex when I don't have a condom available". Participants indicated their agreement with each of the five items measured on a fivepoint Likert scale ranging from strongly agree (for a score of 4) to strongly disagree (for a score of 0 ). A continuous score for condom self-efficacy was used, by summing the scores for all five items. Sex work variables included: number of sex clients in the past month and income in the last month. Women indicated if they currently worked as: a beer promoter, in a beer garden, as a waitress or hostess in a karaoke bar, nightclub, in a massage parlour, brothel, or as a freelance worker in the park, street or another location. FESWs were categorized as entertainment venue-based (i.e., working as beer promoter, in a beer garden, as a waitress or hostess in a karaoke bar, nightclub, in a massage parlour) versus non-entertainment venue-based (i.e., working on the street, brothel or public spaces). In light of the literature linking gender-based violence (from clients and 
intimate partners) with reduced condom negotiation, use and pregnancy $[21,22]$, we also examined the relationship between physical and sexual violence by clients and intimate partners, in the last year.

\section{Statistical analyses}

Pregnancy incidence was calculated using the person-years method. Frequencies and proportions were calculated at baseline for categorical variables, and measures of central tendency (i.e., mean, median and IQR) were used to describe continuous variables. To examine the relationships between potential confounders on time to pregnancy, timedependent Cox regression analyses were used. First, bivariate analyses using an extended Cox regression model were run to estimate the time to pregnancy using unadjusted hazard ratios. Using a conservative $p$-value cut-off of 0.10 , a priori potential confounders that were also significant at $p<0.10$ were included in a full multivariable model (model 1). A second model was constructed with variables significant at $p<0.05$ in bivariate analysis (model 2). All statistical analyses were performed using SAS software version 9.3 (SAS Institute, Cary, NC, USA).

\section{Results}

A total of 204 FESWs were included in our sample, yielding 799 observations over the one-year/12-month follow-up period. More than two thirds of participants (60.3\%) were between the ages of 25-29, with 119 (58.3\%) reporting between one to six years of education. Most participants (63.2\%) were single, divorced, widowed or separated and the median number of children was three (IQR: 2-4) (See Table 1). At baseline, 14 (6.8\%) participants were pregnant, and only $22(10.8 \%)$ reported using hormonal contraceptives (i.e., oral contraceptive pills or injectable hormones), and 23 (11.3\%) reporting an abortion in the past 3 months (Table 2). Pregnancy incidence was high, at 22/100 person-years (py) (95\% CI: 16.3-30.1). The number of new pregnancies at each quarterly time point were as follows: 13, 9, 6 and 13. In bivariate analysis, variables associated with increased pregnancy incidence (at $p<0.10)$ included: age $(19-24$ years versus $25-29$ years); income in the last month $(\leq 600,000$ Riel versus $>600,000$ Riel; the equivalent of $\leq$ \$USD 150 versus >\&USD 150); numbers of years in school (1-6 years versus $7+$ years), cohabiting with a partner (not legally married) compared to living alone (single, widowed, divorced or separated) and hormonal contraceptive use in the last 3 months (measured at baseline). Factors associated with lower pregnancy incidence were HIV-positive serostatus, condom self-efficacy and condom use at last sex.

In multivariable analysis (Model 1), younger age (Adjusted Hazards Ratio (AHR): 2.28; 95\% CI 1.22-4.27), and lower income (AHR 2.63; 95\% CI 1.02-6.77) were independently associated with decreased time to pregnancy.
Self-reported condom self-efficacy was associated with a longer time to incident pregnancy (AHR 0.89; 95\% CI 0. 81-0.98). As displayed in Table 3, similar associations were present in Model 2, a more parsimonious model restricted to factors significant at $p<0.05$ in bivariate analysis.

\section{Discussion}

The one-year pregnancy incidence in this cohort of young FESW was high, even when compared to Cambodia's crude birth rate of 22 live births per 1000 women/year [23]. Moreover, despite the young age of our sample, the median number of children (three) in our cohort exceeded the estimated number of births for urban Cambodian women (2.1 children) over their entire reproductive lives [23]. The finding of high number of pregnancies corroborates a growing body of research, including unintended pregnancies (using abortion rates as a proxy), among women engaged in transactional sex in various settings [4, 8]. For example, 408/475 (86\%) of women in transactional sex in Kenya and 264/514 (53\%) of Colombian women engaged in sex work reported at least one induced abortion [2, 3]. In Uzbekistan, 109/ $448(24.3 \%)$ of women engaged in transactional sex reported three or more lifetime abortions [7]. While there is a need to examine pregnancy intentions among FESW in Cambodia, the high number of abortions in the past three months suggests that many pregnancies in this sample were unintended. Alongside previous research that documented 166/592 (28.2\%) of brothel-based sex workers in Cambodia (in 2007) attending STI care in Phnom Penh had an induced abortion in the last year [24], these findings highlight large reproductive health needs among Cambodian women engaged in commercial sex.

The low use of hormonal contraceptives further underscores the reproductive health gap among FESW in this setting. The baseline prevalence of hormonal contraceptive use in our sample was roughly $23 / 204$ (11\%) compared to 642/2069 (31\%) among Cambodian women living in urban areas [25]. This is especially low when compared to married women in Phnom Penh, (616/1099) 56\% of whom were documented to use hormonal contraceptives in 2010 [25]. Previous research among brothel-based Cambodian women engaged in transactional sex revealed low SRH knowledge, with very few having attended family planning services [26]. Future research into the barriers to SRH services access, including hormonal contraceptives and safe abortion services is warranted. While hormonal contraceptive use in this sample was low, most participants reported using condoms to prevent pregnancy and HIV/STIs. This is not surprising given the dual function of condoms in preventing HIV/STIs and pregnancy, and their relative availability and low cost compared to hormonal contraceptives. The preference for condoms may also reflect Cambodia's 100\% condom use 
Table 1 Baseline characteristics of 204 Female and Entertainment Sex Workers (FESWs) in the YWHS-II study, Phnom Penh, Cambodia

\begin{tabular}{|c|c|c|c|}
\hline Characteristic & $\begin{array}{l}\text { Total }(\%) \\
(n=204)\end{array}$ & $\begin{array}{l}\text { Participants who were } \\
\text { pregnant at least once over } \\
\text { follow-up } \\
\text { Yes }(\%) \\
(n=41)\end{array}$ & $p$-value \\
\hline \multicolumn{4}{|l|}{ Socio-demographics, biological and individual factors } \\
\hline \multicolumn{4}{|l|}{ Age (years) } \\
\hline $16-18$ & $14(6.9)$ & $2(14.3)$ & 0.997 \\
\hline $19-24$ & $67(32.8)$ & $20(29.9)$ & 0.010 \\
\hline $25-29$ & $123(60.3)$ & $19(15.5)$ & - \\
\hline \multicolumn{4}{|l|}{ Income, last month (\$USD) } \\
\hline$\leq 150$ & $128(63.1)$ & $26(20.3)$ & 0.061 \\
\hline$>150$ & $75(36.9)$ & $15(20.0)$ & - \\
\hline \multicolumn{4}{|l|}{ Education } \\
\hline No schooling & $44(21.6)$ & $7(15.9)$ & 0.610 \\
\hline $1-6$ years & $119(58.3)$ & $30(25.2)$ & 0.096 \\
\hline $7+$ years & $41(20.1)$ & $4(9.8)$ & - \\
\hline \multicolumn{4}{|l|}{ Marital status } \\
\hline Legally married & $8(3.9)$ & $1(12.5)$ & 0.321 \\
\hline Living together, not legally married & $67(32.8)$ & $17(25.4)$ & 0.026 \\
\hline Single, widowed, divorced or separated & $129(63.2)$ & $23(17.8)$ & - \\
\hline Number of previous children (continuous) Median, IQR & $3(2-4)$ & $3(2-3)$ & 0.079 \\
\hline \multicolumn{4}{|l|}{ HIV status } \\
\hline HIV positive & $33(16.2)$ & $3(7.3)$ & 0.086 \\
\hline HIV negative & $171(83.8)$ & $38(92.7)$ & - \\
\hline Days drank alcohol, last month & $15(3.5-29.0)$ & $24(3-30)$ & 0.226 \\
\hline ATS use, last 3 months (self-report) & $55(27.0)$ & $12(21.8)$ & 0.569 \\
\hline Condom self-efficacy (median score; IQR) & $21(18-24)$ & $20(17-21)$ & 0.035 \\
\hline Hormonal contraceptive use, last 3 months & $22(10.8)$ & $1(4.6)$ & 0.088 \\
\hline \multicolumn{4}{|l|}{ Interpersonal factors } \\
\hline Used condom at last sex (yes) & $128(62.8)$ & $23(18.0)$ & 0.020 \\
\hline Condom use, last client (yes) & $117(90.0)$ & $23(19.7)$ & 0.772 \\
\hline Condom use, last non-paying partner & $11(14.9)$ & $0(0.0)$ & 0.393 \\
\hline Number of sexual partners, last month Median, IQR & $4(2-10)$ & $3(2-10)$ & 0.790 \\
\hline Any client physical or sexual violence, last year & $53(26.0)$ & $14(26.4)$ & 0.189 \\
\hline Any intimate partner physical or sexual violence, last year & $41(20.1)$ & $9(22.0)$ & 0.957 \\
\hline \multicolumn{4}{|l|}{ Sex work factors } \\
\hline Entertainment venue-based sex work, last month & $131(67.2)$ & $24(18.3)$ & 0.241 \\
\hline Non-entertainment venue-based sex work, last month & $64(32.8)$ & $16(25.0)$ & - \\
\hline Had a manager & $145(71.4)$ & $29(20.0)$ & 0.172 \\
\hline
\end{tabular}

policy for women engaged in transactional sex work, previously enforced widely in brothels; however there is evidence that nation's 2008 anti-trafficking legislation has impeded condom access and use [27]. Condoms as the sole method of contraception can be problematic, given their reduced effectiveness in preventing pregnancy compared to hormonal methods. Dual contraceptive methods (hormonal contraceptives in addition to condom use) are indicated to prevent both HIV/STI and pregnancy in this population. There is an urgent need to explore innovative sex worker-specific service delivery models to improve Cambodian FESWs' access to non-judgmental SRH services that promote dual contraceptive use and safe abortion services. 
Table 2 Pregnancy and HIV/STI prevention methods in the last 3 months, reported at baseline

\begin{tabular}{|c|c|c|c|}
\hline & Total $(100 \%)(n=204)$ & \multicolumn{2}{|c|}{ Participants who were pregnant at least once over the study period } \\
\hline \multicolumn{2}{|c|}{ Method for pregnancy prevention, last 3 months } & Yes $(20.1 \%)(n=41)$ & No $(79.9 \%)(n=163)$ \\
\hline Male condom & $203(99.5)$ & $41(20.2)$ & $162(79.8)$ \\
\hline Withdrawal & $71(34.8)$ & $11(15.5)$ & $60(84.5)$ \\
\hline Oral sex/sex without penetration & $37(18.1)$ & $6(16.2)$ & $31(83.8)$ \\
\hline Birth control pills & $16(7.84)$ & $1(6.2)$ & $15(93.8)$ \\
\hline Injectable contraceptives & $6(2.9)$ & $0(0.0)$ & $6(100.0)$ \\
\hline Abortion & $23(11.3)$ & $6(26.1)$ & $17(73.9)$ \\
\hline Other method & $2(0.98)$ & $0(0.0)$ & $2(100.0)$ \\
\hline \multicolumn{4}{|c|}{ Method for HIV/STI prevention, last 3 months } \\
\hline Male condom & $204(100.0)$ & $41(20.1)$ & $163(79.9)$ \\
\hline Oral sex/sex without penetration & $40(19.6)$ & $8(20.0)$ & $32(80.0)$ \\
\hline Masturbation & 75 (36.8) & $18(24.0)$ & $57(76.0)$ \\
\hline
\end{tabular}

FESW who reported increased self-efficacy or control over condom use had significantly lower pregnancy incidence, likely due to more consistent condom use by sexual partners. While FESWs' ability to negotiate safe sex is critical, growing evidence suggests this needs to be coupled with venue-based interventions that provide access to condoms and support the safe negotiation of condom use by clients $[27,28]$. It is well documented that condom negotiation and use is often beyond the control of women engaged in transactional sex, often due to gender-based violence (and fear of violence), and coerced unprotected sex [29-32]. In this analysis, client physical/sexual violence was associated with elevated pregnancy incidence, though this was not statistically significant. Multi-pronged combined interventions (e.g., safer indoor work spaces, supportive management, FESW mobilization and empowerment) [33] that offer protection against violence within environments that support condom negotiation and use are needed. Cambodia's anti-trafficking legislation and the subsequent displacement of women formerly working in brothels to diverse and sometimes clandestine venues continues to act as an impediment to condom access, venue-based HIV prevention interventions [34] and undermines condom negotiation and access to HIV prevention and SRH services [16, 35]. Indeed, qualitative research among Cambodian FESW has revealed increased vulnerability to sexual and physical violence among those operating out of guesthouses and hotels, in part due to the lack of protection mechanisms previously offered by peers and management in more formal settings [27]. Barriers to HIV care service delivery have also been reported by NGOs following the legislative shift, as FESW have become more difficult to identify and reach [27].

The association between lower income and pregnancy incidence accords with literature documenting greater inconsistent condom use among women engaged in transactional sex with lower socioeconomic status [36].
Possible explanations for this association include the prohibitive costs of hormonal contraceptives and/or barriers to accessing reproductive health services. Lower-income FESW may also be more willing to accept client requests for unprotected sex in an effort to make more money per transaction. Finally, while the association between younger age (19-24 versus 25-29 years) and increased pregnancy incidence in our study warrants further investigation, possible explanations for this association include reduced knowledge of SRH, limited access to SRH services and supplies (e.g., condoms) and lower fertility intentions among older, parous FESW. Given the link between income and pregnancy incidence, structural approaches, such as microfinance or income-generating opportunities warrant investigation [37, 38].

Our findings also have important implications for HIV prevention trials that target FESW. Specifically, high pregnancy incidence may impact recruitment, retention and completion of HIV prevention trials, particularly interventions that require longer-term evaluations such as microbicides and PrEP. Indeed, almost one in ten (7.3\%) women in our study were ineligible to initiate or complete (5.4\%) the three-dose HPV vaccine series offered as part of the YWHS, due to pregnancy within the past six months [39]. These risk-related dropouts potentially bias study samples, impacting generalizability and, in the long term, the efficacy of related future interventions. Given the high burden of unintended pregnancy and low use of hormonal contraceptives among FESW in Cambodia (and elsewhere), there is a need to explore the potential of offering hormonal contraceptives to FESW not desiring pregnancy as part of future HIV prevention interventions.

Our analysis has several limitations. Firstly, the small sample size (and small number of incident pregnancies) may have limited the power of our multivariable analysis and the precision of our estimates. However, the use of multiple responses per participant in this longitudinal 
Table 3 Multivariable Extended Cox analysis of correlates of incident pregnancy among 204 Female and Entertainment Sex workers (799 observations), working in Phnom Penh, Cambodia enrolled in the YWHS-II study

\begin{tabular}{|c|c|c|c|}
\hline Characteristic & Unadjusted Hazard Ratio (HR) & $\begin{array}{l}\text { Adjusted Hazard Ratio (AHR) } \\
\text { MODEL } 1 \text { (FULL) }\end{array}$ & $\begin{array}{l}\text { Adjusted Hazard Ratio (AHR) } \\
\text { MODEL } 2(\operatorname{sig} p<0.05)\end{array}$ \\
\hline \multicolumn{4}{|l|}{ Socio-demographics, biological individual factors } \\
\hline \multicolumn{4}{|l|}{ Age (years) } \\
\hline $16-18$ & $1.00(0.02-4.31)$ & $1.59(0.36-7.11)$ & $1.37(0.31-6.00)$ \\
\hline $19-24$ & $2.28(1.22-4.27)^{*}$ & $3.30(1.57-6.96)^{\dagger}$ & $2.56(1.35-4.87)^{\dagger}$ \\
\hline $25-29$ years & REF & REF & REF \\
\hline \multicolumn{4}{|l|}{ Income, last month (\$USD) } \\
\hline$\leq 150$ & $2.29(0.96-5.44)^{*}$ & $2.63(1.02-6.77)^{\dagger}$ & - \\
\hline$>150$ & REF & REF & - \\
\hline \multicolumn{4}{|l|}{ Education } \\
\hline No schooling & $1.38(0.40-4.70)$ & $1.39(0.38-5.12)$ & - \\
\hline $1-6$ years & $2.43(0.86-6.89)^{*}$ & $1.87(0.64-5.50)$ & - \\
\hline $7+$ years & REF & REF & - \\
\hline \multicolumn{4}{|l|}{ Marital status } \\
\hline Legally married & $2.09(0.49-8.99)$ & $1.42(0.28-7.07)$ & $1.76(0.40-7.66)$ \\
\hline Living together, not legally married & $2.05(1.09-3.84)^{\dagger}$ & $1.92(0.23-15.9)$ & $1.95(1.03-4.71)^{\dagger}$ \\
\hline Single, widowed, divorced or separated & REF & REF & REF \\
\hline Number of previous children & $0.76(0.56-1.03)^{\dagger}$ & $0.67(0.38-1.17)$ & - \\
\hline HIV positive & $0.36(0.11-1.16)^{\dagger}$ & $0.47(0.13-1.63)$ & - \\
\hline Days drank alcohol, last month & $0.77(0.51-1.18)$ & - & - \\
\hline ATS use, last 3 months (self-report) & $0.79(0.35-1.78)$ & - & - \\
\hline Condom self-efficacy $\neq$ & $0.92(0.85-0.99)^{\dagger}$ & $0.89(0.81-0.98)^{\dagger}$ & $0.92(0.84-0.99)^{\dagger}$ \\
\hline Hormonal contraceptive use, last 3 monthsł & $5.63(0.78-41.0)^{*}$ & $0.17(0.02-1.27)$ & - \\
\hline \multicolumn{4}{|l|}{ Interpersonal factors } \\
\hline Condom use, last sex (yes) & $0.45(0.23-0.88)^{\dagger}$ & $0.57(0.28-1.13)$ & - \\
\hline Condom use, last client (yes) & $0.74(0.09-5.81)$ & - & - \\
\hline Condom use, non-paying partner (yes) & $0.53(0.13-2.26)$ & - & - \\
\hline Number of sexual partners, last month & $1.11(0.51-2.41)$ & - & - \\
\hline Client physical or sexual violence, last year & $1.88(0.73-4.85)$ & - & - \\
\hline Intimate partner physical or sexual violence, last year & $0.96(0.23-3.98)$ & - & - \\
\hline \multicolumn{4}{|l|}{ Sex work factors } \\
\hline Entertainment venue-based sex work, last month & $0.67(0.34-1.31)$ & - & - \\
\hline Non- entertainment venue-based sex work, last month & REF & - & - \\
\hline Had a manager & $0.65(0.35-1.21)$ & - & - \\
\hline
\end{tabular}

analysis increased the number of observations, tempering this bias. While the observational nature of this study precludes temporal inference (compared to an experimental study), the longitudinal design serves to strengthen the validity of these findings. Secondly, many of the variables in this analysis (including our pregnancy outcome) were selfreported and may be subject to social desirability bias. Despite this potential limitation, which would bias our results towards the null, significant associations with our outcome remained. Thirdly, we were unable to assess whether the incident pregnancies measured were intended or unintended. Future investigations into the pregnancy intentions/fertility desires of Cambodian FESW are needed. Fourthly, condom self-efficacy and contraceptive usage were only measured at baseline, and thus we were not able to account for changes in these variables over the follow-up period. Fifth, since the 
aim of the study was to examine pregnancy among women in entertainment and sex work venues with high sexual risk patterns, we did not collect data on nor were able to separate female sex workers from entertainment workers with high sexual risk in this analysis. Finally, the clandestine nature of sex work made systematic or probabilistic sampling a challenge, thus limiting the study's generalizability to all young FESW in Cambodia. Despite this drawback, the current sample was able to capture a wide range of FESW working in a variety of sex work settings across Phnom Penh.

\section{Conclusions}

Our results highlight a high incidence of pregnancy and unmet reproductive health need among FESW, with younger age, lower income and low condom-self efficacy associated with reduced time to the occurrence of pregnancy. These findings suggest a need for combined interventions to increase access to SRH services. To be successful, such interventions would need to be supported by legislative and policy shifts that permit FESW to work in safer, more supportive formal indoor settings $[29,33]$. Finally, the high level of pregnancy among FESW observed in the current study has important implications for the SRH rights of FESWs and the recruitment, retention and the success of HIV prevention trials targeting FESW. There is a need to offer SRH information and services to potential HIV prevention trials participants not desiring pregnancy. Access to SRH services may improve trial recruitment and retention and, more importantly, help support the unmet reproductive rights of FESWs.

\begin{abstract}
Abbreviations
ATS: Amphetamine-type stimulants; CWDA: Cambodian Women's Development Association; FESW: Female and Entertainment Sex Workers; HIV: Human Immunodeficiency Virus; HIV/AIDS: Human Immunodeficiency Virus/ Acquired immunodeficiency syndrome; HPV: Human papillomavirus; NCHADS: the National Center for HIV/AIDS, Dermatology and STD; SRH: Sexual and Reproductive Health; STI: Sexually Transmitted Infections; UCSF: the University of California, San Francisco; UNSW: University of New South Wales; YWHS: Young Women's Health Study
\end{abstract}

\section{Acknowledgments}

The authors would like to thank the women who participated in the study and generously shared their expertise with us. The authors would also like to acknowledge the expert leadership and collaboration from partners who were at the Cambodia National Center for HIV/AIDS, Dermatology and STDs at the time this work was conducted, especially Dr. Neth SanSothy, who provided study management and coordination. We also acknowledge our collaborators at the Cambodian Women's Development Agency, especially Keo Sichan. We are also grateful to Cindy Feng, Sabina Dobrer and Melissa Braschel for providing guidance with the statistical analyses for this study.

\section{Funding}

The Young Women's Health Study-2 was supported by an award R01NR010995 from the U.S. National Institutes of Health, National Institute of Nursing Research. Professors Lisa Maher and John Kaldor are supported by Australian National Health and Medical Research Council (NHMRC) Research Fellowships. The Kirby Institute is affiliated with the Faculty of Medicine, University of New South Wales and is funded by the Australian Government Department of Health and Ageing. The content is solely the responsibility of the authors and does not necessarily represent the official views of the National Institutes of Health, nor the Australian Government.

\section{Availability of data and materials}

Data presented in this paper and English versions of the questionnaire are available on request from the Principal Investigator (Kimberly Page: Pagek@salud.unm.edu).

\section{Authors' contributions}

K.P and E.S.S designed the YWHS prospective study and contributed to data acquisition. P.D. and L.M designed the analysis, with input from K.P, E.S.S. and J.L.E. J.L.E. prepared the dataset and advised on statistical analysis. P.D. conducted the statistical analysis, wrote the first draft of the manuscript and incorporated comments and suggestions from all authors. All authors reviewed, provided substantial input and approved the final version of the manuscript.

\section{Ethics approval and consent to participate}

Ethical approval was obtained from the Institutional Review Board of the Committee on Human Research at the University of California, San Francisco, the Cambodian National Ethics Committee and the University of New South Wales Human Research Ethics Committee, aligned with both national and institutional ethical standards and the Helsinki Declaration of 1975 (revised in 2000). The need for parental consent was waived and all participants provided written informed consent prior to participation in the study.

\section{Competing interests}

The authors have no conflicts of interest to declare.

\section{Publisher's Note}

Springer Nature remains neutral with regard to jurisdictional claims in published maps and institutional affiliations.

\section{Author details}

${ }^{1}$ British Columbia Centre for Excellence in HIV/AIDS, St. Paul's Hospital, 608-1081 Burrard Street, Vancouver, BC, Canada. ${ }^{2}$ Department of Medicine, University of British Columbia, St. Paul's Hospital, 608-1081 Burrard Street, Vancouver, BC, Canada. ${ }^{3}$ Institute for Global Health, Department of Epidemiology, University of California-San Francisco, San Francisco, California, USA. ${ }^{4}$ Division of Epidemiology, Biostatistics and Preventive Medicine, Department of Internal Medicine, University of New Mexico Health Sciences Center, Albuquerque, NM, USA. ${ }^{5}$ Kirby Institute for Infection and Immunity (formerly the National Centre in HIV Epidemiology and Clinical Research), UNSW Australia I, Wallace Wurth Building, Sydney, NSW 2052, Australia. ${ }^{6}$ Cambodian Women's Development Association (CWDA, No. 19, Street 242, Boeung Prolit, Khan 7 Makara, Phnom Penh, Cambodia. 7 Department of Medicine, University of California San Francisco, 513 Parnassus Ave; UCSF, San Francisco, CA, USA. ${ }^{8}$ National Center for HIV/AIDS, Dermatology and STDs (NCHADS), \#245H, Street 6A, Phum Kean Khlang, Sangkat Prekleap Russey Keo, Phnom Penh, Cambodia.

Received: 16 February 2016 Accepted: 24 April 2018

Published online: 03 May 2018

\section{References}

1. Becker M, Ramanaik S, Halli S, Blanchard JF, Raghavendra T, Bhattacharjee P, Moses S, Avery L, Mishra S. The intersection between sex work and reproductive health in northern Karnataka, India: identifying gaps and opportunities in the context of HIV prevention. AIDS research and treatment. 2012;2012:-842576.

2. Bautista CT, Mejía A, Leal L, Ayala C, Sanchez JL, Montano SM. Prevalence of lifetime abortion and methods of contraception among female sex workers in Bogota, Colombia. Contraception. 2008;77(3):209-13.

3. Elmore-Meegan M, Conroy RM, Agala CB. Sex workers in Kenya, numbers of clients and associated risks: an exploratory survey. Reprod Health Matters. 2004;12(23):50-7.

4. Duff $P$, Shoveller J. High lifetime pregnancy and low contraceptive usage among sex workers who use drugs-an unmet reproductive health need. BMC Pregnancy Childbirth. 2011;11:61. 
5. Feldblum PJ, Nasution MD, Hoke TH, Van Damme K, Turner AN, Gmach R, Wong EL, Behets F. Pregnancy among sex workers participating in a condom intervention trial highlights the need for dual protection. Contraception. 2007;76(2):105-10

6. Yam EA, Mnisi Z, Sithole B, Kennedy C, Kerrigan D, Tsui A, Baral S. Association between condom use and use of other contraceptive methods among female sex Workers in Swaziland: a relationship-level analysis of condom and contraceptive use. Sex Transm Dis. 2013;40(5):406-12.

7. Todd CS, Alibayeva G, Sanchez JL, Bautista CT, Carr JK, Earhart KC. Utilization of contraception and abortion and its relationship to HIV infection among female sex workers in Tashkent, Uzbekistan. Contraception. 2006;74(4):318-23.

8. Delvaux T, Crabbe F, Seng S, Laga M. The need for family planning and safe abortion services among women sex workers seeking STI care in Cambodia. Reprod Health Matters. 2003;11(21):88-95.

9. Beckham SW, Shembilu Cr Fau - Brahmbhatt H, Brahmbhatt H Fau - Winch PJ, Winch Pj Fau - Beyrer C, Beyrer C Fau - Kerrigan DL, Kerrigan DL: Female sex workers' experiences with intended pregnancy and antenatal care services in southern Tanzania. (0039-3665 (Print)).

10. Duff P, Shoveller J, Feng C, Ogilvie G, Montaner J, Shannon K: Pregnancy intentions among female sex workers: recognising their rights and wants as mothers. (2045-2098 (Electronic)).

11. Schwartz S, Papworth E Fau - Thiam-Niangoin M, Thiam-Niangoin M Fau Abo K, Abo K Fau - Drame F, Drame F Fau - Diouf D, Diouf D Fau - Bamba A, Bamba A Fau - Ezouatchi R, Ezouatchi R Fau - Tety J, Tety J Fau - Grover E, Grover E Fau - Baral S et al: An urgent need for integration of family planning services into HIV care: the high burden of unplanned pregnancy, termination of pregnancy, and limited contraception use among female sex workers in Cote d'Ivoire. (1944-7884 (Electronic)).

12. Zhang XD, Kennedy E Fau - Temmerman M, Temmerman M Fau - Li Y, Li Y Fau - Zhang W-H, Zhang Wh Fau - Luchters S, Luchters S: High rates of abortion and low levels of contraceptive use among adolescent female sex workers in Kunming, China: a cross-sectional analysis. (1473-0782 (Electronic)).

13. Swain SN, Saggurti N, Battala M, Verma RK, Jain AK. Experience of violence and adverse reproductive health outcomes, HIV risks among mobile female sex workers in India. BMC Public Health. 2011;11:357.

14. Weldegebreal R, Melaku YA, Alemayehu M, Gebrehiwot TG: Unintended pregnancy among female sex workers in Mekelle city, northern Ethiopia: a cross-sectional study. (1471-2458 (Electronic)).

15. Page K, Stein E, Sansothy N, Evans J, Couture MC, Sichan K, Cockroft M, Mooney-Somers J, Phlong P, Kaldor J, et al. Sex work and HIV in Cambodia: trajectories of risk and disease in two cohorts of high-risk young women in Phnom Penh, Cambodia. BMJ Open. 2013;3(9):e003095.

16. Maher L, Dixon T, Phlong P, Mooney-Somers J, Stein E, Page K. Conflicting rights: how the prohibition of human trafficking and sexual exploitation infringes the right to health of female sex Workers in Phnom Penh, Cambodia. Health Hum Rights. 2015;17(1):E102-13.

17. UNAIDS: More women in Cambodia turning to sex trade amid financial crisis. In.; 2009

18. United Nations Development Program. Sex work and the law in Asia and the Pacific. Bangkok: UNDP; 2012.

19. Francis C: HIV prevention and anti-trafficking in conflict? The public health consequences of Cambodia's fight against trafficking. In.: FHI (in collaboration with PSI, Care, UNAIDS); 2008.

20. Nemoto T, Iwamoto M, Colby D, Witt S, Pishori A, Le MN, Vinh DT, Giang Le T. HIV-related risk behaviors among female sex workers in ho chi Minh City, Vietnam. AIDS Educ Prev. 2008;20(5):435-53.

21. Decker MR, Pearson E, Illangasekare SL, Clark E, Sherman SG. Violence against women in sex work and HIV risk implications differ qualitatively by perpetrator. BMC Public Health. 2013;13(1):876.

22. Deering KN, Amin A, Shoveller J, Nesbitt A, Garcia-Moreno C, Duff P, Argento E, Shannon K. A systematic review of the correlates of violence against sex workers. Am J Public Health. 2014;104(5):e42-54.

23. National Institutes of Statistics. Cambodia demographic health survey, 2014: key indicators report. Phnom Penh: National Institutes of Statistics; 2015.

24. Morineau G, Neilsen G, Heng S, Phimpachan C, Mustiakawati D. Falling through the cracks: contraceptive needs of female sex workers in Cambodia and Laos. Contraception. 2011;84:194-8.

25. National Institue of Statistics. Directorate General for Health, Macro I: Cambodia Demographic and Health Survey, 2010. Phnom Penh, Cambodia and Calverton, Maryland: National Institute of Statistics, Directorate General for Health, and ICF Macro; 2011.
26. Delvaux T, Crabbé F, Seng S, Laga M. The need for family planning and safe abortion services among women sex workers seeking STI care in Cambodia. Reproductive Health Matters. 2003;11(21):88-95.

27. Maher L, Mooney-Somers J, Phlong P, Couture M-C, Stein E, Evans J, Cockroft M, Sansothy N, Nemoto T, Page K. Selling sex in unsafe spaces: sex work risk environments in Phnom Penh, Cambodia. Harm reduction journal. 2011;8(1):30.

28. Krüsi A, Chettiar J, Ridgway A, Abbott J, Sa S, Shannon K. Negotiating safety and sexual risk reduction with clients in unsanctioned safer indoor sex work environments: a qualitative study. Am J Public Health. 2012;102(6):1154-9.

29. Shannon K, Sa S, Goldenberg SM, Duff P, Mwangi P, Rusakova M, Reza-Paul S, Lau J, Deering K, Pickles MR, et al. Global epidemiology of HIV among female sex workers: influence of structural determinants. Lancet. 2014;6736(14)

30. Goldenberg SM, Duff P, Krusi A. Work environments and HIV prevention: a qualitative review and meta-synthesis of sex worker narratives. BMC Public Health. 2015:15:1241

31. Tan SY, Melendez-Torres GJ. A systematic review and metasynthesis of barriers and facilitators to negotiating consistent condom use among sex workers in Asia. Cult Health Sex. 2015:1-16.

32. Andrews $\mathrm{CH}$, Faxelid E, Sychaerun V, Phrasisombath K. Determinants of consistent condom use among female sex workers in Savannakhet, Lao PDR. BMC Womens Health. 2015;15:63.

33. Duff P, Shoveller J, Dobrer S, Ogilvie G, Montaner J, Chettiar J, Shannon K. The relationship between social, policy and physical venue features and social cohesion on condom use for pregnancy prevention among sex workers: a safer indoor work environment scale. (1470-2738 (Electronic)).

34. Couture M-C, Sansothy N, Sapphon V, Phal S, Sichan K, Stein E, Evans J, Maher L, Kaldor J, Vun MC, et al. Young women engaged in sex work in Phnom Penh, Cambodia, have high incidence of HIV and sexually transmitted infections, and amphetamine-type stimulant use: new challenges to HIV prevention and risk. Sex Transm Dis. 2011;38(1):33-9.

35. UNAIDS: Cambodia Country Progress Report: Monitoring the Progress towards the Implementation of the Declaration of Commitment on HIV and AIDS. In.: Prepared by National AIDS Authority for United Nations General Assembly Special Session (UNGASS); Reporting period: January 2010-2011.

36. Chen Y, Li X, Zhou Y, Wen X, Wu D: AlDS Care : Psychological and Sociomedical Aspects of AIDS/HIV Perceived peer engagement in HIV-related sexual risk behaviors and self-reported risk-taking among female sex workers in Guangxi, China. 2013(March):37-41.

37. Dworkin SL, Blankenship K. Microfinance and HIV/AIDS prevention: assessing its promise and limitations. AIDS Behav. 2009;13(3):462-9.

38. Witte SS, Aira T, Tsai LC, Riedel M, Offringa R, Chang M, El-Bassel N, Ssewamala F. Efficacy of a savings-led microfinance intervention to reduce sexual risk for HIV among women engaged in sex work: a randomized clinical trial. Am J Public Health. 2015;105(3):e95-102.

39. Wadhera P, Evans JL, Stein E, Gandhi M, Couture MC, Sansothy N, Sichan K, Maher L, Kaldor J, Page K, et al. Human papillomavirus knowledge, vaccine acceptance, and vaccine series completion among female entertainment and sex workers in Phnom Penh, Cambodia: the young Women's health study. Int J STD AIDS. 2015;26(12):893-902.

\section{Ready to submit your research? Choose BMC and benefit from:}

- fast, convenient online submission

- thorough peer review by experienced researchers in your field

- rapid publication on acceptance

- support for research data, including large and complex data types

- gold Open Access which fosters wider collaboration and increased citations

- maximum visibility for your research: over $100 \mathrm{M}$ website views per year

At BMC, research is always in progress.

Learn more biomedcentral.com/submissions 